Old Dominion University

ODU Digital Commons

VMASC Publications

Virginia Modeling, Analysis \& Simulation Center

2013

\title{
Special Issue: M\&S Optimization Applications in Industry and Engineering, Part 2
}

Rafael Diaz

Old Dominion University, rdiaz@odu.edu

Andreas Tolk

Old Dominion University

Follow this and additional works at: https://digitalcommons.odu.edu/vmasc_pubs

Part of the Software Engineering Commons

\section{Repository Citation}

Diaz, Rafael and Tolk, Andreas, "Special Issue: M\&S Optimization Applications in Industry and Engineering, Part 2" (2013). VMASC Publications. 32.

https://digitalcommons.odu.edu/vmasc_pubs/32

\section{Original Publication Citation}

Diaz, R., \& Tolk, A. (2013). Special issue: M\&S optimization applications in industry and engineering, part 2. Simulation: Transactions of the Society for Modeling and Simulation International, 89(9), 1039-1040. doi:10.1177/0037549713505361

This Editorial is brought to you for free and open access by the Virginia Modeling, Analysis \& Simulation Center at ODU Digital Commons. It has been accepted for inclusion in VMASC Publications by an authorized administrator of ODU Digital Commons. For more information, please contact digitalcommons@odu.edu. 


\section{Special issue: M\&S optimization applications in industry and engineering, part 2}

\section{Rafael Diaz and Andreas Tolk}

Welcome to the second part of the special issue on modeling and simulation (M\&S) optimization applications in industry and engineering. This issue incorporates additional publications that reflect various applications and areas of simulation and optimization.

As indicated in the first part of this special issue, the progress in computational power has permitted the characterization and resolution of complex problems using heuristic optimizations and M\&S outside synthetic environments, to better support academicians and practitioners. This has increased the range of design and analysis approaches to examine and understand complex engineering and business systems. This second part of the special issue focuses on highlighting further applications of $\mathrm{M} \& \mathrm{~S}$ and optimization to solve complex problems as well as proposing effective heuristics that improve application analyses. This special issue consists of six paper contributions, briefly described as follows.

Khodabakhshian et al. introduce a novel optimization method for designing the parameters of a power system stabilizer (PSS) that employs a smart bacteria foraging algorithm (SBFA). In this sense, the suggested approach that extends the bacteria foraging method (BFA) may guide bacteria by using a tumble with a smart unit of length. This effectively decreases the cost function when compared to conventional BFA. This procedure considers social intelligence while emphasizing the individual intelligence of bacteria for seeking a better nutritional path. Higher convergence speeds than traditional BFA as well as better performance have been obtained when using this approach. The authors used simulations to compare this new approach with conventional PSS as well as BFA- and fuzzy-based PSS methods. They found that the new approach reports a superior performance for damping power system oscillations.

Eguia et al. propose a new approach to simultaneously solve the cell formation and the scheduling of part families for an effective working of a reconfigurable cellular manufacturing system (RCMS). They used a new mixed integer linear programming model to characterize problems whose goal are minimizing production costs. The authors considered two types of production costs that include reconfiguration costs and underutilization costs for not using the reconfigurable machine tools (RMT) resources. Computational experiments have been performed to examine the ability of the proposed approach to find goodquality production schedules of part families in a RCMS without requiring long computing times. Results show that the proposed procedure may efficiently solve real-world problems.

The paper from Czop and his colleagues provide a mathematical approach for minimizing the vibrations produced by hydraulic dampers constrained by keeping the same damping force characteristics. The authors employ a model-based approach to obtain the optimal pressure flow via simulations performed using coupled models. They structured their work around five specific goals that include (1) developing/adapting a double-tube damper model; (2) defining critical parameters of the valve characteristics influencing the high-frequency piston-rod acceleration; (3) identifying parameter values using two alternative methods that include a short version of design of experiment (DOE) and nonlinear programming; (4) obtaining the optimal pressure-flow characteristic by means of simulation; and (5) performing an experimental analysis that compares high-frequency contents of acceleration using a laboratory setup.

Barszcz and Czop present a simulation-optimization application for the tuning of the first-principle model of a feedwater heater operating in a coal-fired power. The goal of this study was to find the most efficient and accurate algorithm to tune the model parameters, namely, heat transfer coefficients. The model variables and estimated values were used to characterize fundamental performance

Old Dominion University, Virginia Modeling, Analysis, and Simulation Center, Department of Engineering Management, Norfolk, VA, USA

\section{Corresponding author:}

Rafael Diaz, Old Dominion University, Virginia Modeling, Analysis, \& Simulation Center, Department of Engineering Management, 5 I I 5 Hampton Boulevard, Norfolk, VA 23529, USA.

Email: rdiaz@odu.edu 
indicators. This was intended for structuring a modeldriven diagnostics approach. This search was organized in an iterative process in which model parameters and indicators were updated sequentially.

Felez et al. characterize a simulation model able to mimicking large-scale traffic in an urban environment. These authors worked toward formulating a realistic and detailed simulation of the traffic while reproducing the individual behavior of each vehicle. The goal was to develop a model to be incorporated in an immersive driving simulator. In this simulator, the driving position is the focus of the simulation and the traffic model mimics events around them. This traffic model is applicable to large-scale traffic simulation that integrates an immersive driving simulator and is very useful when investigating complex behaviors of these environments. The model has been validated through comparisons with results obtained from various references, with very satisfactory results.

Hagendorf et al. propose an approach that provides optimization through automatic reconfiguration of both the model structure and model parameters for modeling and simulation. The method employs an evolutionary algorithm sustained by a model management method. Furthermore, this approach is grounded on the system entity structure/model base framework. By employing the system entity structure ontology, model structures and associated parameter sets are established. Thus, different system configurations may be automatically assessed using both an evolutionary algorithm and a model management operating collectively.

\section{Acknowledgements}

Besides all the contributors we thank also Dr Yilmaz, Dr Wainer, and Mrs Vicki Pate, and all our peer reviewers for their support in the preparation of this special issue.

\section{Author biographies}

Rafael Diaz is research assistant professor of modeling and simulation at Old Dominion University's Virginia Modeling, Analysis, and Simulation Center (VMASC). He is currently the director of the Advanced Analytics Research Laboratory at VMASC. He holds an MBA with a focus on financial analysis and information technology and $\mathrm{a} \mathrm{PhD}$ in modeling and simulation, both from Old Dominion University, as well as an ME in project management from Andres Bello Catholic University and a BS in industrial engineering from Jose Maria Vargas University, Venezuela.

Andreas Tolk is Chief Scientist at SimIS Inc. and adjunct professor for engineering management and systems engineering at Old Dominion University. He holds a $\mathrm{PhD}$ and $\mathrm{MSc}$ in computer science, both from the University of the Federal Armed Forces of Germany. He is a senior member of IEEE and SCS and a member of ACM SIGSIM. 